\title{
Pawel Brzegowy, review of: Julia Estela Monárrez Fragoso, Trama de una injusticia. Feminicidio sexual sistémico en Ciudad Juárez, México D.F. 2009, p. 322.
}

The monographic study authored by Julia Estela Monárrez Fragoso tackles the uneasy problem area of human rights violation in Mexico, which is illustrated with the example of femicide in Ciudad Juárez. At the same time, the study constitutes an appeal to the national and international public opinion, aimed at starting a fight against the disgraceful dealings. In her study, the author asks a few attention-grabbing questions, regarding, not only the origin and character of feminicidio (femicide), but also its impact on the victims' families. In the chapter entitled "Feminismo y violencia de género", it was noted that due to the machismo-marianismo historical model, established in the social system, and the man's explicit patriarchalism towards the woman resulting from it, various forms of violence are justified and full gender equality is negated. As it is generally known, the machismo culture is a set of behaviours and values, characterised by the increased sense of masculinity and its strong manifestation. Not infrequently, do the exaltation of the physical advantage and brutal force remain its indispensable attribute. Ciudad Juárez, localised in northern Mexico, excellently illustrates the dramatic scale of violence against women. Drug gang wars, sexism - which were given a closer look in the study, homicides and abductions resulted in the loss of the sense of safety and increase of asocial behaviours in the city. The principal source of income for the residents of Ciudad Juárez are numerous factories, specialising in subcontracted work, called the maquiladoras. By the very fact that the same act as the key employer for the majority of women employed thereby, in her study, the author analyses the positive and negative effects of their existence, both in the economic and social dimension. The efforts undertaken by the successive governments to protect the women's rights have not yielded the desired effect so far, whereas the violence inflicted against the Mexican women constitutes an evident violation of human rights and a real barrier obstructing the gender equality. Isn't Ciudad Juárez a symbol of national disgrace?

On the successive pages of the study authored by Monárrez Fragoso - the researcher of El Colegio de la Frontera Norte con sede en Ciudad Juárez, we are getting familiar with the historical outline of the local femicide, which is assumed to have originated in 1993. Almost each successive murder, committed throughout the several recent years, was connected with explicit cruelty involving: rapes, tortures and profanations of the corpse. In the opinion of Monárrez Fragoso, a sexual intercourse marked with violence is the expression of the man's dominating role, which, simultaneously, makes him a decision maker, determining the fate of the woman viewed as an inferior (weaker) being. Numerous decomposing corpses were, not infrequently, found in the close vicinity to the maquiladoras. Even the incompletely preserved carcasses demonstrated the enormous degeneration of the torturers and scale of the inflicted injuries. The profiles of the majority of the murdered victims are similar, these are usually teenage girls and young women. The women that are particularly vulnerable to the attacks are the ones who finish work late at night and return home by factory buses. The majority of the victims used to reside in the most impoverished peripheral city districts, the so-called 'risk zones', devoid of electricity, water distribution or sewage disposal systems. The author accuses the authorities of the Chihuahua State of pursuing a women's discrimination policy. She 
points to the local office clerks' and police officers' incompetency and tolerance for crime. She stresses that in the 90s of the previous century, Ciudad Juárez experienced a substantial growth of the culture of intolerance against women, which directly affected the number of murders. In numerous cases, these were motivated by the sexual factor. What is particularly painful, is the fact that the Mexican authorities frequently happened to present the femicide phenomenon as a kind of myth. Numerous acts of violence against women are not even registered, whereas the omnipresent corruption and disregard for biological evidence seriously obstruct counteracting crime. The researcher also tackles the issue of psychological support, addressed at the victims' families, and expressly appeals for the introduction of changes into the state criminal code. In the present study, the activities of numerous institutions and organisations, such as: Oficina de las Naciones Unidas contra la Droga y el Delito, Comisión Nacional de los Derechos Humanos and others, were referred to and their reports and dissertations were quoted. Monárrez Fragoso underlines that the Mexican femicide is an issue of global importance and an undisputed manifestation of crime against humanity, committed with the participation of the international organised crime and state officials of various ranks. The author seeks for the reasons, underlying the continuing drama, mainly, in the activities of the international gangs specialising in drug trade and expresses her regret over the depravation of the state justice enforcement system. For various organised criminal gangs, Ciudad Juárez is a popular venue of conflicting interests. The existence of numerous drug distribution points in the city testifies to the scale of the problem. In the author's opinion, demoralisation of security forces, manifesting itself in the corruption and cooperation with drug cartels, is a serious threat. This generates the atmosphere of distrust and hostility towards the police. However, the precise determination of the corruption scale is a problematic issue.

It was strongly accentuated in the study that in Mexico there is no space for hatred towards women while the democratic character of the state requires the reinforcement of the rule of law, which is the basic value in the human rights protection system. The femicide, ceaselessly continued in Ciudad Juárez for 20 years, resulting mostly from sexism, is a violation of the principle of a law-governed state, which Mexico aspires to pass for and is mostly caused by the drug-culture, corruption and malfunction of the national internal security system. In the shape of the monographic study Trama de una injusticia. Feminicidio sexual sistémico en Ciudad Juárez, the reader receives the true image of the tragic condition of the Mexican human rights protection system, whose weakest element are women. May the country, which expresses an explicit consent to the mass-scale slaughtering of women, pass for a law-governed state? At present, there seems to be only one response to the question asked in this manner... 